\title{
Distillation Time Effect on Essential Oil Yield, Composition, and Antioxidant Capacity of Sweet Sagewort (Artemisia annua L.) Oil
}

\author{
Valtcho D. Zheljazkov ${ }^{1}$ \\ University of Wyoming, Sheridan Research and Extension Center, 663 \\ Wyarno Road, Sheridan, WY 82801 \\ Tess Astatkie \\ Dalhousie University, Faculty of Agriculture, 50 Pictou Road, P.O. Box 550, \\ Truro, Nova Scotia B2N 5E3, Canada
}

Thomas Horgan

Mississippi State University, North Mississippi Research and Extension Center, 5421 Highway 145 South, Verona, MS 38879

Vicki Schlegel

University of Nebraska-Lincoln, Department of Food Science and Technology, 327Food Technology Complex, Lincoln, NE 68583

\section{Xavier Simonnet}

Mediplant, Swiss Research Centre on Medicinal and Aromatic Plants, Route des Vergers 18, 1964 Conthey, Switzerland

Additional index words. sweet sagewort, steam distillation, essential oil yield, camphor, betacaryophyllene, eucalyptol, geramacrene-D

\begin{abstract}
Sweet sagewort, also known as sweet wormwood (Artemisia annua L.), contains essential oil and other natural products. The objective of this study was to evaluate the effect of eight different distillation times (DTs; 1.25 minutes, 2.5 minutes, 5 minutes, 10 minutes, 20 minutes, 40 minutes, 80 minutes, and 160 minutes) on $A$. annua essential oil and its antioxidant capacity. Highest essential oil yield was achieved at 160-minute DT. The concentration of camphor $(8.7 \%$ to $50 \%$ in the oil) was highest at the shorter DT and reached a minimum at 160-minute DT. The concentration of borneol showed a similar trend as the concentration of camphor. The concentrations of some constituents in the oil were highest at 2.5-minute DT (alpha-pinene and camphene), at 10 minutes (paracymene), at 20 minutes (beta-chamigrene and gamma-himachalene), at 80 minutes [transmuurola-4(15),5-diene and spathulenol], at 80- to 160-minute DT (caryophylene oxide and cis-cadin-4-en-ol), or at 160-minute DT (betacaryophyllene, transbeta-farnesene, and germacrene-D). The yield of individual constituents reached maximum at 20- to 160-minute DT (camphor) at 80- to 160-minute DT [paracymene, borneol, transmuurola-4(15),5-diene, and spathulenol], or at 160-minute DT (for the rest of the oil constituents). DT can be used to attain $A$. annua essential oil with differential and possibly targeted specific chemical profile. The highest antioxidant capacity of the oil was obtained at 20-minute DT and the lowest from the oil in the 5-minute DT. This study suggests that literature reports on essential oil content and composition of $A$. annua could be compared only if the essential oil was extracted at similar DTs. Therefore, DT must be reported when reporting data on essential oil content and composition of $A$. annua.
\end{abstract}

Artemisia annua is a multiuse medicinal plant that contains several natural products such as essential oil and antioxidant flavonoids (Ferreira et al., 2010) and is used currently as

Received for publication 3 June 2013. Accepted for publication 10 Aug. 2013.

This research was funded by ARS Specific Cooperative Agreement 58-6402-4-026 with CRIS MIS-172050 (research grant "Medicinal Herbs Research in Mississippi” awarded to Dr. Jeliazkov [Zheljazkov]).

${ }^{1}$ To whom reprint requests should be addressed; e-mail vjeliazk@uwyo.edu, Valtcho.pubs@gmail.com. the only commercial source of artemisinin. Artemisinin is used as the raw material for production of artemisinin-based combination therapies (ACT) such as the first line of defense against multidrug-resistant Plasmodium falciparum malaria (Ferreira et al., 2010).

For essential oil production, A. annua is cultivated in large areas of eastern Europe (Bulgaria, Hungary, and Romania), and the essential oil is extracted through steam distillation of the biomass (Nedkov and Attanassova, 2004). The essential oil of $A$. annua has applications in perfumery and cosmetics and in aromatherapy (Nedkov and Attanassova, 2004). The wide application of the A. annua essential oil is not only the result of its fine aroma, but also the result of the reported antifungal and antibacterial activities (Juteau et al., 2002), insecticidal activity (Tripathi et al., 2009), antioxidant activity (Cavar et al., 2012), and, partially, the result of the long history of this plant used as a medicinal plant in a number of traditional medicines in the Mediterranean region (Stojanov, 1973).

Like with other aromatic plants, $A$. annua essential oil content and composition is modified by genotype and the environment (Tzenkova et al., 2010), by distillation method (Scheffer, 1993), and by other factors. A recent report (Ferreira et al., 2013) found that the DT affected essential oil content, artemisinin concentration, and antioxidant capacity of the plant residue from distillation of $A$. annua. Steam DT has been shown to significantly affect essential oil composition of other aromatic plants such as Japanese cornmint (Mentha canadensis L.) (Zheljazkov and Astatkie, 2012b), pine (Pinus ponderosa Dougl. ex Laws) (Zheljazkov et al., 2012a), oregano (Origanum vulgare L.) (Zheljazkov et al., 2012b), female and male Rocky Mountain juniper (Juniperus scopulorum Sarg.) (Zheljazkov et al., 2012c, 2013), peppermint (Mentha $x$ piperita L.), lemongrass (Cymbopogon flexuosus Steud.), and palmarosa (Cymbopogon martinii Roxb.) (Cannon et al., 2013). However, the effect of DT on $A$. annua essential oil composition and on the yield of various oil constituents is unknown. We hypothesized that DT will have a significant effect on $A$. annua essential oil composition and yield of oil constituents and thus the antioxidant capacity. The objective of this study was to evaluate the effect of eight DTs on A. annua essential oil yield and composition, yield of oil constituents, and associated antioxidant capacity.

\section{Materials and Methods}

Plant material and essential oil distillation conditions. The plant material used in this study was obtained from field trials conducted in Mississippi (at the North Mississippi Research and Extension Center in Verona, MS, at lat. $34^{\circ} 43^{\prime} 22^{\prime \prime} \mathrm{N}$ and long. $88^{\circ} 43^{\prime} 22^{\prime \prime}$ W). Certified seeds of $A$. annua were kindly provided by Mediplant, Switzerland. Seedlings were produced in a greenhouse and were transplanted out in the field and grown as described previously (Ferreira et al., 2013). The plants were transplanted in raised beds with plastic mulch in the spring of 2008. The plantation in 2009 and in 2010 was established by self-seeding of plants from the previous year. Samples for this study were generated in the fall of 2010 by harvesting whole plants.

The essential oil was extracted from fresh biomass in 2-L steam distillation units (Hearthmagic, Rancho Santa Fe, CA), as described previously (Ferreira et al., 2013; Gawde et al., 2009; Zheljazkov et al., 2010). The size of all samples was $500 \mathrm{~g}$; samples included leaves and branches not thicker than $2 \mathrm{~mm}$. The DTs 
were $1.25,2.5,5,10,20,40,80$, and $160 \mathrm{~min}$, all conducted in three replicates. These DTs were selected based on literature reports and a previous study by Ferreira et al. (2013). The length of each DT was measured from the moment that the first drop of essential oil was deposited in the separator. At the end of each DT, the separator part was removed from the apparatus, and the collected essential oil plus some water was decanted into a glass vial. The essential oil was separated from water by placing the samples in a freezer and decanting the oil after the water was frozen. The oil yield (content) was calculated as the weight ( $\mathrm{g}$ ) of oil per weight (g) of fresh $A$. annua biomass.

Gas chromatography analysis of essential oil. The essential oil samples of $A$. annua (all in three replicates) were analyzed on a Hewlett Packard (Hewlett-Packard, Palo Alto, CA) gas chromatograph (GC) model 6890 fitted with an autosampler. The carrier gas was helium, $40 \mathrm{~cm} \cdot \mathrm{sec}^{-1}, 11.7 \mathrm{psi}\left(60^{\circ} \mathrm{C}\right), 2.5$ $\mathrm{mL} \cdot \mathrm{min}^{-1}$ constant flow rate; the injection split $60: 1,0.5 \mu \mathrm{L}$, the injector temperature was $220{ }^{\circ} \mathrm{C}$; and the oven temperature program as follows: $60^{\circ} \mathrm{C}$ for $1 \mathrm{~min}, 10^{\circ} \mathrm{C} / \mathrm{min}$ to $250^{\circ} \mathrm{C}$. The GC column was HP-INNOWAX (Hewlett-Packard; crosslinked polyethylene glycol; $30 \mathrm{~m} \times 0.32 \mathrm{~mm} \times 0.5 \mu \mathrm{m}$ ), and the flame ionization detector temperature was $275^{\circ} \mathrm{C}$. The identification of individual peaks was done using internal standards by retention time and by mass spectroscopy.

Oxygen radical capacity. The antioxidant capacity of the oil extracts was determined by the oxygen radical absorbance capacity

Table 1. Mean essential oil (EO) content (\%, as the weight of oil per weight of fresh $A$. annua biomass) and the concentrations (\% of total oil) of alpha-pinene, camphene, paracymene, eucalyptol, camphor, borneol, and beta-caryophyllene obtained from the eight distillation times (DTs).

\begin{tabular}{|c|c|c|c|c|c|c|c|c|}
\hline $\mathrm{DT}(\min )$ & EO content & Alpha-pinene & Camphene & Paracymene & Eucalyptol & Camphor & Borneol & Beta-caryophyllene \\
\hline 1.25 & $0.005 \mathrm{f}^{z}$ & $1.2 \mathrm{abc}$ & $1.8 \mathrm{bc}$ & $1.2 \mathrm{e}$ & $3.5 \mathrm{~b}$ & $50.4 \mathrm{a}$ & $1.6 \mathrm{a}$ & $5.2 \mathrm{de}$ \\
\hline 2.50 & $0.04 \mathrm{e}$ & $2.1 \mathrm{a}$ & $3.5 \mathrm{a}$ & $2.9 \mathrm{bc}$ & $5.9 \mathrm{a}$ & $49.9 \mathrm{a}$ & $2.0 \mathrm{a}$ & $4.1 \mathrm{e}$ \\
\hline 5 & $0.05 \mathrm{de}$ & $1.9 \mathrm{ab}$ & $3.3 \mathrm{ab}$ & $3.1 \mathrm{bc}$ & $5.1 \mathrm{a}$ & $47.5 \mathrm{a}$ & $1.9 \mathrm{a}$ & $4.8 \mathrm{de}$ \\
\hline 10 & $0.05 \mathrm{de}$ & $1.9 \mathrm{ab}$ & $3.0 \mathrm{ab}$ & $4.7 \mathrm{a}$ & $5.8 \mathrm{a}$ & $36.8 \mathrm{~b}$ & $1.0 \mathrm{~b}$ & $6.3 \mathrm{~d}$ \\
\hline 20 & $0.07 \mathrm{~d}$ & $1.7 \mathrm{ab}$ & $2.8 \mathrm{ab}$ & $3.7 \mathrm{ab}$ & $3.6 \mathrm{~b}$ & $33.3 \mathrm{bc}$ & $1.0 \mathrm{~b}$ & $8.3 \mathrm{c}$ \\
\hline 40 & $0.11 \mathrm{c}$ & $1.2 \mathrm{bc}$ & $2.0 \mathrm{bc}$ & $2.6 \mathrm{bcd}$ & $2.4 \mathrm{bc}$ & $27.0 \mathrm{c}$ & $0.9 \mathrm{~b}$ & $9.1 \mathrm{c}$ \\
\hline 80 & $0.18 \mathrm{~b}$ & $0.84 \mathrm{c}$ & $1.4 \mathrm{c}$ & $2.0 \mathrm{cde}$ & $1.7 \mathrm{c}$ & $16.8 \mathrm{~d}$ & $0.8 \mathrm{~b}$ & $11.8 \mathrm{~b}$ \\
\hline 160 & $0.23 \mathrm{a}$ & $0.51 \mathrm{c}$ & $0.9 \mathrm{c}$ & $1.6 \mathrm{de}$ & $1.1 \mathrm{c}$ & $8.7 \mathrm{e}$ & $0.3 \mathrm{c}$ & $14.3 \mathrm{a}$ \\
\hline
\end{tabular}

${ }^{\mathrm{z}}$ Within each column, means sharing the same letter are not significantly different at the $5 \%$ level.
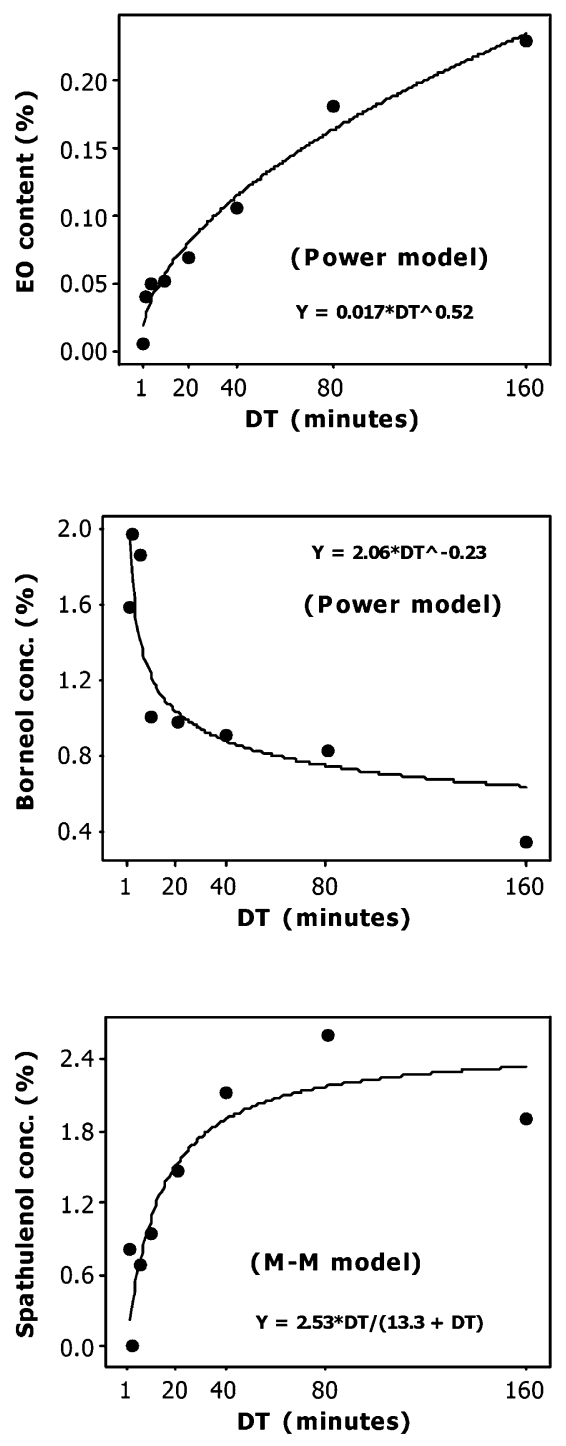


Fig. 1. Plots of essential oil (EO) content and the concentrations of eight constituents vs. distillation times along with the fitted power, exponential, and MichaelisMenton (M-M) nonlinear regression models. Equations of the fitted models are shown within each plot. 
method (Huang et al., 2002a, 2002b) and as described in more detail previously (Zheljazkov et al., 2012b, 2013).

Statistical analysis. The effect of DT on essential oil content as well as the concentration and yield of alpha-pinene, camphene, paracymene, eucalyptol, camphor, borneol, beta-caryophyllene, transbeta-farnesene, beta-chamigrene, germacrene- $\mathrm{D}$, gammahimachalene, transmuurola-4(15),5-diene, spathulenol, caryophyllene oxide, and ciscadin-4-en-ol was determined using a oneway analysis of variance. For each response variable, the validity of normal distribution and constant variance assumptions on the error terms was verified by examining the residuals as described in Montgomery (2013). The effect of DT was significant $(P<0.05)$ on all responses. Consequently, multiple means comparison was completed using Duncan's multiple range test method at the $5 \%$ level of significance to generate letter grouping. The analysis was completed using the GLM Procedure of SAS (SAS Institute Inc., 2010).

The relationship between DT and most of the concentration and yield response variables was adequately modeled (Bates and Watts, 2007) by either the Michaelis-Menten (eq. [1]) or the power (eq. [2]) or the exponential (eq. [3]) model. All these three models are nonlinear (Bates and Watts, 2007). However, the relationship between DT and some concentration and yield response variables was either very weak or there was no identifiable regression model. The parameters of these nonlinear models were estimated iteratively using the NLIN Procedure of SAS (SAS Institute Inc., 2010).

$$
\begin{aligned}
& Y=\frac{\theta_{1} x}{\theta_{2}+x}+\varepsilon \\
& Y=\theta_{1} x^{-\theta_{2}}+\varepsilon \\
& Y=\theta_{1} \exp \left(\theta_{2} x\right)+\varepsilon
\end{aligned}
$$

where $Y$ is the dependent (response) variable, $x$ is the independent (DT) variable, and the error term $\epsilon$ is assumed to have normal distribution with constant variance.

\section{Results}

Distillation time affected $A$. annua essential oil content $(0.005 \%$ to $0.23 \%)$ (Table 1 ; Fig. 1). Essential oil content increased with longer DT and reached a maximum at 160 $\min$ DT.

The concentrations of alpha-pinene $(0.5 \%$ to $2.1 \%$ of the oil) and camphene $(0.9 \%$ to $3.5 \%$ ) were highest at $2.5-\mathrm{min}$ DT and lowest at 160-min DT (Table 1; Fig. 1). The concentration of paracymene $(1.2 \%$ to $4.7 \%)$ was lower at 1.25-min DT, increased and reached its maximum at 10 -min DT, and gradually decreased with further increase of DT. The concentration of eucalyptol (1.1\% to $5.9 \%$ in the oils) was higher from 2.5- to 10-min DT and decreased with further increase in DT to reach a minimum at 80 - to 160 -min DT. The concentration of the main oil constituent camphor $(8.7 \%$ to $50 \%)$ was highest at the shorter DT of 1.25- to 5-min DT and then gradually decreased with increasing DT to reach a minimum at $160-\mathrm{min}$ DT. The concentration of borneol $(0.3 \%$ to $2 \%)$ showed a similar trend as the concentration of camphor. The concentrations of beta-caryophyllene ( $4.1 \%$ to $14.3 \%$ range) (Table 1 ; Fig. 1 ), transbeta-farnesene $(2.9 \%$ to $5.6 \%$ range), and germacrene-D (5.5\% to $23.1 \%$ range) increased with an increase in DT and reached a maximum at 160 -min DT (Table 2). The concentrations of beta-chamigrene $(1.1 \%$ to $2.1 \%)$ and gamma-himachalene $(1.2 \%$ to $1.9 \%$ ) were lower at $2.5-\mathrm{min}$ DT and reached their respective maximums at $20-$ min DT. The concentrations of transmuurola-4(15),5diene $(0.3 \%$ to $5.7 \%$ range) and spathulenol ( $0 \%$ to $2.6 \%$ range) reached maximum at 80 min DT. The concentrations of caryophylene oxide and cis-cadin-4-en-ol $(0.9 \%$ to $4.3 \%$ range) reached maximum at $80-$ to $160-\mathrm{min}$ DT (Table 2; Fig. 1).

The yield of the individual oil constituents (a function of essential oil yield and the concentration of each individual oil constituent) generally increased with an increase in DT and reached maximum at 20 - to $160-\mathrm{min}$ DT (camphor), at 80- to 160-min DT [paracymene, borneol, transmuurola-4(15),5-diene, and spathulenol], or at 160-min DT (for the rest of the oil constituents) (Fig. 2). The yield of alpha-pinene (average $1.0 \mathrm{mg}$ ), camphene (average of $1.7 \mathrm{mg}$ ), and eucalyptol (average of $2.4 \mathrm{mg}$ ) were unaffected by the DT.

The relationships between DT and the concentrations and yields shown in Figures 1 and 2 were very well described either by the power or the exponential or the MichaelisMenten model. Although some are almost perfectly modeled and others are not so perfect, all the fitted models shown in the plots can be used to predict the concentrations and yields for any given DT. For the power model, the first parameter $\left(\theta_{1}\right)$ estimated by $0.017 \%$ (Fig. 1) for essential oil content shows what can be extracted at DT of $1 \mathrm{~min}$, and the second parameter $\left(\theta_{2}\right)$ estimated by 0.52 for essential oil content shows the rate of increase as DT is increased. For the exponential model, the first parameter $\left(\theta_{1}\right)$ estimated by $48.9 \%$ (Fig. 1) for the concentration of camphor shows the concentration at the beginning of distillation (DT of $0 \mathrm{~min}$ ), and the second parameter $\left(\theta_{2}\right)$ estimated by -0.014 for the concentration of camphor shows its decay rate as DT is increased. For the MichaelisMenten model, the first parameter $\left(\theta_{1}\right)$ estimated by $2.53 \%$ (Fig. 1 ) for the concentration of spathulenol shows the maximum achievable concentration, and the second parameter $\left(\theta_{2}\right)$ estimated by $13.3 \mathrm{~min}$ for the concentration of spathulenol shows the DT needed to achieve $50 \%$ of the maximum concentration.

The $A$. annua essential oil had the lowest antioxidant capacity at 5-min and 80-min DT and the highest at 20-min DT. However, the antioxidant capacity of the essential oils from 10-min and 160-min DT was not significantly different from the other DT extracting times.

\section{Discussion}

The hypothesis of this study was confirmed by the results of this study; DT had a significant effect on both the essential oil composition and the yield of individual oil constituents. In addition, DT had a significant effect on antioxidant capacity of the essential oil. Increase of DT up to $160 \mathrm{~min}$ resulted in an increase in oil yield (content). We did not perform longer DTs because a previous study by Ferreira et al. (2013) with the same genotype of $A$. annua and from the same fields found no significant difference in essential oil content between 160- and 240-min DT. This study supports other reports that DT can alter essential oil yield and composition of a number of crop species (Cannon et al., 2013; Zheljazkov and Astatkie, 2012a, 2012b; Zheljazkov et al., 2012a, 2012b, 2012c, 2013).

The essential oil composition of $A$. annua in this study was somewhat different from the one in some previous reports (Malik et al., 2009; Tzenkova et al., 2010). For example, the main oil constituents of $A$. annua in Malik et al. (2009) were artemisia ketone,

\begin{tabular}{|c|c|c|c|c|c|c|c|c|}
\hline $\begin{array}{l}\text { DT } \\
(\min )\end{array}$ & $\begin{array}{l}\text { Transbeta- } \\
\text { farnesene }\end{array}$ & Beta-chamigrene & Germacrene-D & $\begin{array}{c}\text { Gamma- } \\
\text { himachalene }\end{array}$ & $\begin{array}{l}\text { Transmuurola- } \\
4(15), 5 \text {-diene }\end{array}$ & Spathulenol & $\begin{array}{c}\text { Caryophyllene } \\
\text { oxide }\end{array}$ & Cis-cadin-4-en-ol \\
\hline 1.25 & $4.5 b^{z}$ & $1.7 b c$ & $6.4 \mathrm{e}$ & $1.6 \mathrm{abc}$ & $\begin{array}{r}\text { otal oil----- } \\
1.6 \mathrm{~d}\end{array}$ & $0.8 \mathrm{~d}$ & $0.5 \mathrm{c}$ & $1.4 \mathrm{de}$ \\
\hline 2.50 & $2.9 \mathrm{c}$ & $1.1 \mathrm{e}$ & $5.5 \mathrm{e}$ & $1.2 \mathrm{e}$ & $1.6 \mathrm{~d}$ & $0.0 \mathrm{e}$ & $0.0 \mathrm{~d}$ & $0.9 \mathrm{e}$ \\
\hline 10 & $4.2 \mathrm{~b}$ & $1.9 \mathrm{ab}$ & $7.2 \mathrm{de}$ & $1.7 \mathrm{ab}$ & $1.5 \mathrm{~d}$ & $0.9 \mathrm{~d}$ & $0.7 \mathrm{c}$ & $1.8 \mathrm{~d}$ \\
\hline 20 & $3.7 \mathrm{bc}$ & $2.1 \mathrm{a}$ & $8.8 \mathrm{~d}$ & $1.9 \mathrm{a}$ & $2.4 \mathrm{c}$ & $1.5 \mathrm{c}$ & $1.0 \mathrm{~b}$ & $2.8 \mathrm{c}$ \\
\hline 40 & $4.1 \mathrm{~b}$ & $2.0 \mathrm{ab}$ & $11.0 \mathrm{c}$ & $1.7 \mathrm{ab}$ & $3.2 \mathrm{~b}$ & $2.1 \mathrm{~b}$ & $1.2 \mathrm{ab}$ & $3.4 \mathrm{bc}$ \\
\hline
\end{tabular}

Table 2. Mean concentrations (\% of total oil) of transbeta-farnesene, beta-chamigrene, germacrene-D, gamma-himachalene, transmuurola-4(15),5-diene, spathulenol, caryophyllene oxide, and cis-cadin-4-en-ol obtained from the eight distillation times (DTs).

${ }^{\mathrm{z}}$ Within each column, means sharing the same letter are not significantly different at the $5 \%$ level. 

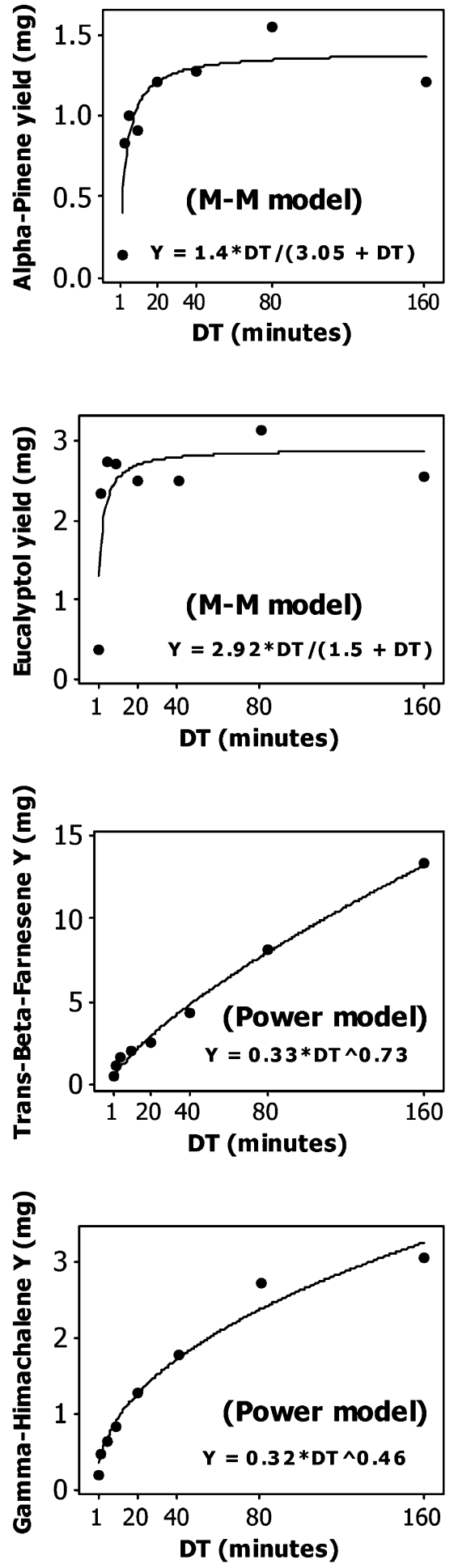
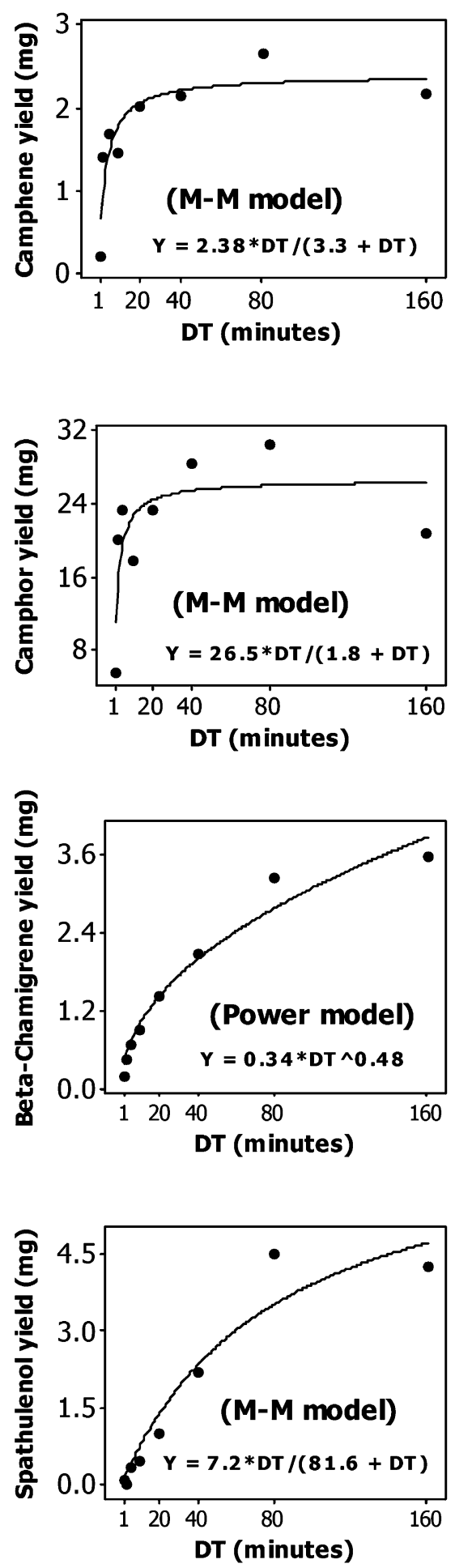
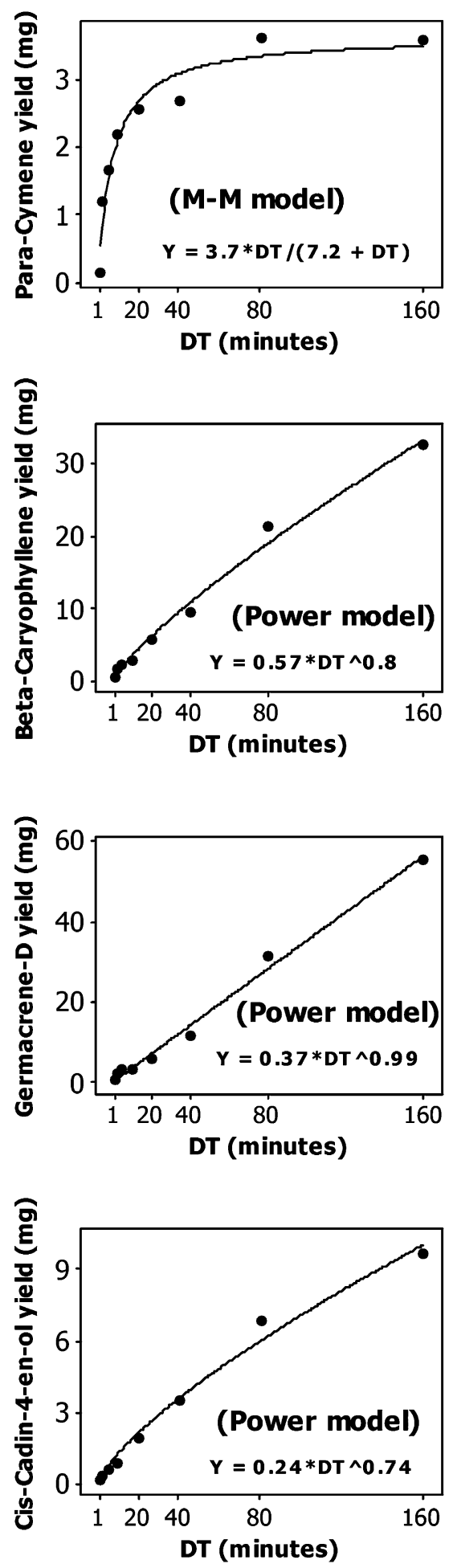

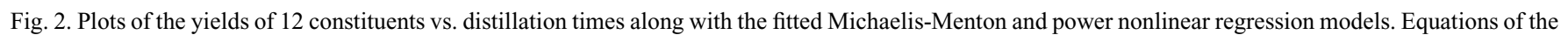
fitted models are shown within each plot.

iso-pinocamphone, thujyl alkohol, and camphor, whereas the main oil constituents in the study of Tzenkova et al. (2010) were alphacaryophyllene, alpha-cuvebene, alpha-copaene, alpha selinene, and camphor. Because Malik et al. (2009) distilled the biomass for $4 \mathrm{~h}$, and Tzenkova et al. (2010) distilled it for $2.5 \mathrm{~h}$, it is difficult to judge if these differences were the result of genotype, the environment, or the DT. However, the concentration of camphor in this study was similar to the one reported by Bagchi et al. (2003), who found $10.4 \%$ to $44.4 \%$ camphor in A. annua in the subtropical north Indian plains. Charles et al. (1989) also reported camphor (28\%), alpha-pinene (16\%), and 1,8 cineole $(23 \%)$ to be some of the major A. annua essential oil constituents. In addition, Holm et al. (1997) reported camphor ( $7 \%$ to $44 \%$ ), artemisia ketone, germacrene-D, and b-caryophyllene as the major constituents of essential oil of $A$. апnua with different origin.

The antioxidant capacity was relatively similar across DTs with the notable exception of DT 5- and 20-min extracts. The different compositional profiles of the oils obtained at various DTs are most likely contributing factors affecting the antioxidative capacity. Similarly, Melo et al. (2005) reported that different aqueous extractions of coriander 
containing higher total phenols did not translate into higher antioxidative capacity. These results were attributed to the different types and ratios of phenolic compounds present in each. In this study, comparison of the percent essential oils obtained at the different DT (Table 1) showed statistically different amounts of most of the individual oil constituents. As a result, no one essential oil constituent or even group of constituents can be proposed as the responsible component for this effect. Rather, the various composition profiles as a complete group must act together to affect the antioxidant capacity. However, more studies are needed to understand the possible synergists, or even antagonists, in each of these complex oil extracts.

Our study demonstrated that DT can be used as a simple method to obtain $A$. annua with differential chemical profiles. For example, if a high-camphor oil is desirable, $A$. annua needs to be distilled for only 1.25- to 5-min DT. If high concentrations of betacaryophyllene, transbeta-farnenesene, or geracrene-D are desirable, $A$. annua needs to be distilled for $160 \mathrm{~min}$.

An important connotation for the results of this study is authors must not compare literature reports on essential oil content and composition of $A$. annua unless these reports used similar DTs for extracting the essential oil. Therefore, DTs must be reported when reporting data on essential oil content and composition of $A$. annua.

\section{Literature Cited}

Bagchi, G.D., F. Haider, P.D. Dwivedi, A. Singh, and A.A. Naqvi. 2003. Essential oil constituents of $A$. апnи a during different growth periods at monsoon conditions of subtropical North Indian plains. J. Essent. Oil Re. 15:248-250.

Bates, D.M. and D.G. Watts. 2007. Nonlinear regression and its applications. Wiley, New York, NY

Cannon, J.B., C.L. Cantrell, T. Astatkie, and V.D. Zheljazkov. 2013. Distillation time modifies yield and composition of peppermint, lemongrass, and palmarosa essential oils. Ind. Crops Prod. 41:214-220.
Cavar, S.A., M. Maksimovic, D. Vidica, and A. Paric. 2012. Chemical composition and antioxidant and antimicrobial activity of essential oil of Artemisia annua L. from Bosnia. Ind. Crops Prod. 37:479-485.

Charles, D.J., E. Cebert, and J.E. Simon. 1989. Characterization of the essential oil of Artemisia annua L. J. Essent. Oil Res. 3:33-39.

Ferreira, J.F.S., D.L. Luthria, T. Sasaki, and A. Heyerick. 2010. Flavonoids from Artemisia annua L. as antioxidants and their potential synergism with artemisinin against malaria and cancer. Molecules 15:3135-3170.

Ferreira, J.F.S., V.D. Zheljazkov, and J.M. Gonzales. 2013. Artemisinin concentration and antioxidant capacity of Artemisia annua distillation byproduct. Ind. Crops Prod. 41:294-298.

Gawde, A.J., C.L. Cantrell, and V.D. Zheljazkov. 2009. Dual extraction of essential oil and podophyllotoxin from Juniperus virginiana. Ind. Crops Prod. 30:276-280.

Holm, Y., I. Laakso, R. Hiltunen, and B. Galambosi. 1997. Variation in the essential oil composition of Artemisia annua L. of different origin cultivated in Finland. Flavour Frag. 12:241-246.

Huang, D., B. Ou, M. Hampsch-Woodill, J. Flanagan, and E.K. Demmer. 2002a. Development and validation of oxygen radical absorbance capacity assay for lipophilic antioxidants using randomly methylate B-cylodextrin as the solubility enhancer. J. Agr. Food Chem. 50:1815-1821.

Huang, D., B. Ou, M. Hampsch-Woodill, J. Flanagan, and R. Prior. 2002b. High-throughput assay of oxygen radical absorbance capacity (ORAC) using a multichannel liquid handling system coupled with a microplate fluorescence reader in 96-well format. J. Agr. Food Chem. 50: 4437-4444.

Juteau, F., V. Masotti, J.M. Bessiere, M. Dherbomez, and J. Viano. 2002. Antibacterial and antioxidant activities of Artemisia annиa essential oil. Fitoterapia 73:532-535.

Malik, A.A., J. Ahmad, S.R. Mir, A. Mohammed, and M.Z. Abdin. 2009. Influence of chemical and biological treatments on volatile oil composition of Artemisia апnиа Linn. Ind. Crops Prod. 30:380-383.

Melo, E. de A., J.M. Filho, and N.B. Guerra. 2005. Characterization of antioxidant compounds in aqueous coriander extract (Coriandrum sativum L.). LWT-Food Sci Technol. 38:15-19.

Montgomery, D.C. 2013. Design and analysis of experiments. $8^{\text {th }}$ Ed. Wiley, New York, NY.
Nedkov, N. and M. Attanassova. 2004. Essential oil and medicinal crops. Kameja Press, Sofia, Bulgaria.

SAS Institute Inc. 2010. SAS/STAT ${ }^{\circledR} 9.3$ user's guide. SAS Institute Inc., Cary, NC.

Scheffer, J. 1993. The isolation of essential oilsFactors influencing the oil composition. Acta Hort. 334:2-8.

Stojanov, N.S. 1973. Our medicinal plants. Part II. Nauka and Izkustvo (Science and Art) Press, Sofia, Bulgaria.

Tripathi, A.K., V. Prajapati, K.K. Aggarwal, S.P.S. Khanuja, and S. Kumar. 2009. Repellency and toxicity of oil from Artemisia annua to certain stored-product beetles. J. Econ. Entomol. 93:43-47.

Tzenkova, R., Z. Kamenarska, A. Draganov, and A. Atanassov. 2010. Composition of Artemisia aпnиa essential oil obtained from species growing wild in Bulgaria. Biotechnol., Biotechnol. Equip. 24:1833-1835.

Zheljazkov, V.D. and T. Astatkie. 2012a. Distillation waste water can modify peppermint (Mentha $\times$ piperita L.) oil composition. Ind. Crops Prod. 36:420-426.

Zheljazkov, V.D. and T. Astatkie. 2012b. Effect of distillation time on Mentha canadensis essential oil yield and composition. HortScience 47:643-647.

Zheljazkov, V.D., T. Astatkie, E.A. Jeliazkova, A.O. Tatman, and V. Schlegel. 2013. Distillation time alters essential oil yield, composition and antioxidant activity of female Juniperus scopulorum trees. J. Essent. Oil Res. 25:62-69.

Zheljazkov, V.D., T. Astatkie, and V. Schlegel. 2012a. Effects of distillation time on the Pinus ponderosa essential oil yield, composition, and antioxidant activity. HortScience 47:785-789.

Zheljazkov, V.D., T. Astatkie, and V. Schlegel. 2012b. Distillation time changes oregano essential oil yields and composition but not the antioxidant or antimicrobial activities. HortScience 47:777-784.

Zheljazkov, V.D., T. Astatkie, E.A. Jeliazkova, and V. Schlegel. 2012c. Distillation time alters essential oil yield, composition, and antioxidant activity of male Juniperus scopulorum trees. J. Oleo Sci. 61:537-546.

Zheljazkov, V.D., C.L. Cantrell, T. Astatkie, and A. Hristov. 2010. Yield, content, and composition of peppermint and spearmints as a function of harvesting time and drying. J. Agr. Food Chem. 58:11400-11407. 